\title{
BUDIDAYA DAN PEMANFAATAN SAGU (Metroxylon Sp.) OLEH SUB-ETNIS AYAMARU DI KAMPUNG SEMBARO DISTRIK AYAMARU SELATAN
}

\section{(Plantation and Usage of Sago [Metroxylon Sp.] by Ayamaru Sub-Ethnicity in Sembaro Village of South Ayamaru Sub-District)}

\author{
Fransiska Asmuruf ${ }^{1}$ Jimmy F. Wanma $^{1 凶}$ dan Alexander Rumatora ${ }^{1}$ \\ Jurusan Kehutanan, Fakultas Kehutanan Universitas Papua Manokwari, Papua Barat, \\ 98314. Tlp/Fax: +62986211065 . \\ ${ }^{\square}$ Penulis Korespondensi: Email: jimmywanma@yahoo.com \\ Diterima: 20 Sept 2018| Disetujui: 14 Oct 2018
}

\begin{abstract}
Abstrak
Penelitian ini bertujuan untuk mengetahui kearifan lokal dalam budidaya dan pemanfaatan tanaman sagu oleh sub-etnis Ayamaru di Distrik Ayamaru Selatan. Guna mendapatkan informasi, metode survei digunakan untuk melihat bentuk pengolahan dan pemanfaatan tanaman sagu dan untuk mengetahui pola pengelolaan berbasis budaya maka digunakan teknik diskusi semi struktural dengan panduan quisioner. Hasil penelitian memperlihatkan bahwa tanaman sagu sangat penting dalam budaya masyarakat sehingga informasi terkait pengelolaan dan pemanfaat tanaman sagu diturunkan dalam struktur komunitas masyarakat. Terdapat dua jenis kultivar sagu yang dimanfaatkan yakni sagu 'Akek' dan sagu 'Koror' yang sama-sama merupakan jenis sagu berduri namun secara morfologi memiliki perbedaan pada diameter batang, tinggi, ukuran daun, warna empulur dan produktifitasnya. Usia ideal tanaman sagu yang siap dipanen di atas 7 tahun dan rata-rata produksi aci yang dihasilkan antara 10 hingga $15 \mathrm{~kg}$.
\end{abstract}

Kata kunci: Budidaya, sagu berduri, pengolahan sagu, aci sagu, kearifan lokal

\begin{abstract}
In general, this study highlights the importance of local knowledge and cultural perspective in dealing with the use of sago plant by sub-ethnic Ayamaru in south Ayamaru sub district. In order to gain information, survey method has been applied to identify types of management and usage from sago plant. To understand the management pattern that bases on culture, then discussion through semi-structural interview with questionnaires were carried out. The result revealed that sago plant is still pivotal in the cultural based community, so a lot of related information in conjunction with sago plant will pass over their generations in the community. There were two sago plant cultivar that found namely 'Akek' dan sagu 'Koror' and both were thorny variety. However, they were different in morphological attributes such as diameter, height, leaf size, pith color, and their productivity. The ideal age of the plant to be harvested was a minimum of seven years and it will be decent to be more than that age with an average starch production of between 10 up to $15 \mathrm{~kg}$.
\end{abstract}

Keywords: Plantation, thorny sago, sago management, sago starch, local custom 


\section{PENDAHULUAN}

Hutan adalah sumberdaya alam yang dapat diperbaharui dan memiliki keanekaragaman hayati yang sangat tinggi serta berperan penting dalam kepentingan nasional dan internasional. Manfaat hutan tidak hanya secara ekonomis tetapi juga ekologis. Hutan bagi masyarakat Papua berfungsi sebagai tempat berlindung, mencari makan, berburu dan penghasil bahan baku kayu dan non kayu untuk kebutuhan sehari-hari (Lekitoo et al. 2017). Hutan juga merupakan sumber daya alam yang tidak hanya menghasilkan kayu sebagai hasil hutan utama, tetapi hasil ikutan seperti hasil hutan bukan kayu (non kayu). Sagu termasuk hasil hutan non kayu yang telah lama menjadi komoditi perdagangan. Data statistik kehutanan menunjukan bahwa rata-rata nilai ekspor hasil hutan non kayu mencapai $24 \%$ dari seluruh devisa hasil hutan (Alhamid dkk. 1996).

Jika dilihat dari keragaman dan keaslian sagu di Indonesia diperkirakan berasal dari daerah Maluku dan Papua, karena pada kedua daerah ini dijumpai hutan sagu dengan banyak ragam seperti sagu berduri dan tidak berduri. Papua diperkirakan terdapat 980.000 ha hutan sagu dan 14.000 ha kebun sagu dengan daerah penyebaran meliputi wilayah Salawati, Teminabuan, Bintuni, Mimika, Merauke, Wasior, Serui, Waropen, Mamberamo, Sarmi dan Sentani (Flach 1983).

Sagu adalah komoditi tanaman pangan yang digunakan sebagai sumber karbohidrat yang cukup potensial di Indonesia. Khususnya di wilayah bagian timur Indonesia sagu belum dimanfaatkan secara optimal pada hal sagu memiliki peranan penting pada berbagai bidang, meskipun saat ini sagu masih berkembang secara tradisional dan terbatas. Di Indonesia peranan sagu sangat mendukung pelaksanaan Inpres No.20 tahun 1979 tentang usaha diversifikasi pangan karena potensi produksinya tinggi dan berpeluang besar sebagai makanan yang disukai masyarakat.

Sagu dikenal oleh sebagian besar masyarakat papua sebagai tumbuhan serba guna selain sumber patinya dimanfaatkan untuk makanan pokok dalam bentuk olahan papeda, sagu lempeng dan sinoli. Bagian-bagian lain dari tumbuhan ini dimanfaatkan untuk berbagai keperluan hidup seperti daun untuk atap rumah, pelepah daun untuk dinding rumah, kulit batang untuk lantai rumahataupun sebagai bahan kayu bakar dan pucuk daun sebagai sayur (Kadiwaru 2004; Payai 2008).

Etnis Maybrat merupakan salah satu etnis di Papua yang mendiami daerah Kepala Burung pulau Papua. Etnis ini memiliki tiga sub etnis yakni Ayamaru, Aitinyo dan Aifat. Masyarakat diketiga Sub Etnis tersebut diketahui sejak lama dan turun temurun telah memanfaatkan tumbuhan dalam memenuhi kebutuhan hidup sehari-hari. Hal ini dapat dilihat dari beberapa produk seperti noken/tas, bangunan rumah, bahan pangan, bahan obat-obatan tradisional dan barang lainnya yang digunakan oleh masyarakat setempat yang merupakan hasil olahan dari tumbuhan (Assem dkk. 2018). Begitupula dengan tumbuhan sagu yang telah dimanfaatkan dalam kehidupan dan budaya masyarakat etnis Maybrat. Namun tidak semua etnis Maybrat memanfaatkan tumbuhan sagu seperti pada sub etnis Ayamaru yang hanya beberapa daerah 
saja yang terdapat tumbuhan sagu dan dimanfaatkan untuk keperluan hidup. Dengan demikian, penelitian ini bertujuan untuk mengetahui kearifan lokal dalam budidaya dan pemanfaatan tanaman sagu oleh etnis Maybrat.

\section{METODE PENELITIAN}

Penelitian ini dilaksanakan di Kampung Sembaro Distrik Ayamaru Selatan Kabupaten Maybrat dengan lama waktu penelitian sekitar satu bulan yakni dari bulan Juli s/d bulan Agustus tahun 2015.

\section{Subjek dan Objek Penelitian}

Dalam penelitian ini yang menjadi subjek penelitian adalah masyarakat peramu sagu. Sementara yang menjadi objek penelitian yaitu cara dan teknik budidaya serta pemanfaatan sagu yang dilakukan oleh masyarakat peramu sagu. Penelitian ini menggunakan metode deskriptif dengan teknik observasi lapangan dan wawancara semi struktural yang mengacu pada kuisioner. Sehingga keterlibatan responden menjadi komponen penting dalam kegiatan penelitian ini. Penentuan responden dalam penelitian ini dilakukan secara proposif yang terbagi menjadi dua bagian yaitu responden kunci (key respondent) dan responden umum (common respondent). Responden kunci terdiri dari kepala kampung dan tokoh adat, sedangkan responden umum yaitu masyarakat yang mengetahui cara budidaya dan pemanfaatan sagu yang berdomisili di Kampung Sembaro dengan persentasi 30\% dari total peramu sagu.

\section{Variabel Pengamatan}

Variabel dalam penelitian ini di bagi menjadi dua yaitu variabel utama dan variabel penunjang. Variabel utama meliputi kegiatan budidaya yang terdiri dari pembibitan, penanaman, pemeliharaan dan pemanenan. Selain itu kegiatan pemanfaatan mengcover bagian-bagian dari tanaman sagu yang dimanfaatkan, bentuk pemanfaatan, proses pemanfaatan dan cara pemanfaatannya dengan mengacu pada kuisioner yang telah disiapkan dan observasi lapangan. Sementara variabel penunjang yaitu data-data dari instansi dan stakeholder terkait yang berkaitan dengan penelitian.

\section{Pengumpulan Data}

Data yang dikumpulkan dalam penelitian ini terdiri dari data primer dan data sekunder. Data primer merupakan data yang diperoleh secara langsung melalui wawancara dengan responden dan obsevasi dilapangan. Data primer terdiri dari kegiatan budidaya dan pemanfaatan.Sedangkan data sekunder yaitu keadaan umum lokasi penelitian seperti iklim, tanah, topografi, jumlah penduduk dan keadan sosial masyarakat.

\section{Analisis Data}

Data yang diperoleh dalam penelitian ini akan dianalisis secara deskriptif dan disajikan dalam bentuk tabel dan gambar (foto).

\section{HASIL DAN PEMBAHASAN}

Sagu memegang peranaan penting bagi kehidupan sosial budaya masyarakat Papua termasuk masyarakat Suku Maybrat Sub-etnis Ayamaru di Kampung Sembaro. Pada kampung ini pohon sagu dimanfaatkan secara maksimal untuk memenuhi kebutuhan hidup sehari-hari masyarakat lokal. Selain itu, untuk melestarikan pohon sagu masyarakat juga 
melakukan kegiatan budidaya berbasis pengetahuan lokal yang diperoleh berdasarkan pengalaman visual mereka secara turum temurun. Secara umum pengetahuan local di Papua menjadi kunci penting pemanfaat hasil hutan dan diperoleh secara turun temurun (Marwa et al. 2013)

Di Kampung Sembaro terdapat dua kultivar sagu yang di kelola oleh masyarakat yaitu sagu 'Akek' dan sagu 'Koror'. Kedua kultivar ini tergolong dalam tipe sagu berduri yang dibedakan berdasarkan diameter batang, tinggi, ukuran daun, warna empulur dan produktifitasnya serta dalam pemanfaatannya juga yang terdapat perbedaan yang berarti.

\section{Budidaya}

\section{Pembibitan}

\section{Tipe bibit}

Secara umum pembibitan tanaman dilakukan dengan dua cara, yaitu menggunakan bahan generatif dan bahan vegetatif, begitupula untuk tanaman sagu. Tanaman ini oleh sebagian besar masyarakat Papua dibudidayakan menggunakan bahan vegetatif yaitu tunas. Disamping itu terdapat beberapa daerah yang menggunakan bahan generatif, salah satunya seperti masyarakat Inanwatan di Kabupaten Sorong (Salosa 1997).

Pembibitan dengan bahan vegetatif dipilih oleh sebagian besar masyarakat Papua sebagai usaha budidaya sagu karena menurut masyarakat lebih cepat tumbuh dibandingkan dengan menggunakan bahan generatif (biji) yang sangat sulit tumbuh. Seperti halnya masyarakat Kampung Sembaro hanya menggunakan tunas gantung/menempel dalam kegiatan budidaya sagu. Tunas tempel dipilih karena bagi masyarakat bibit seperti ini tidak memerlukan ketrampilan khusus pada waktu pengambilan dan penanamannya serta memiliki keberhasilan tumbuh yang baik berdasarkan pengalaman mereka. Tunas sagu yang dipilih dan diambil untuk dijadikan bibit hanya berasal dari rumpun sagu yang produktifitasnya tinggi dan rasanya lebih enak yang menurut masyarakat Kampung Sembaro. Pemilihan tersebut biasanya dilakukan karena masyarakat pernah menanam sagu dari rumpun tersebut dengan hasil pati \pm 7-12 karung15 kg per pohon.

Beberapa hasil penelitian sagu di Papua menunjukkan bahwa masyarakat lokal Papua kebayakan menggunakan tunas sebagai bahan untuk pembudidayaan sagu. Hal ini diungkapkan dalam penelitian Kadiwaru (2004) maupun Fahutan UNIPA (2014) yang menyatakan bahwa masyarakat Kampung Poom I di Kabupaten Kepulauan Yapen menggunakan tunas dalam kegiatan budidaya sagu.

Menurut masyarakat Kampung Sembaro, pembibitan menggunakan bahan vegetatif berupa tunas lebih baik karena dapat tumbuh dengan cepat, sedangkan pembibitan dengan cara generatif melalui biji tidak dilakukan karena kebanyakan biji terserang hama dan penyakit serta sulit untuk tumbuh. Bibit yang diambil berasal dari tunas yang tumbuh pada bagian pangkal batang (tunas gantung/menempel). Hal serupa juga dilakukan oleh masyarakat Sentani di Kampung Nendali Distrik Sentani Kabupaten Jayapura (Suebu 2005) dan masyarakat Inanwatan di Kabupaten Sorong, walaupun ada juga yang masih mengecambahkan biji sagu (Salosa 1997).

Pengambilan tunas tempel yang akan dijadikan bibit oleh masyarakat Kampung 
Sembaro dapat berasal dari pohon sagu belum masak tebang ataupun pohon sagu masak tebang (siap panen) yang memiliki 1-3 tunas gantung yang menempel. Jumlah tunas gantung yang akan dijadikan bibit berada antara pohon sagu belum masak tebang dan pohon sagu masak tebang. Pada pohon sagu masak tebang tunas tempel yang dijadikan bibit dapat diambil lebih dari satu, sedangkan pada pohon sagu belum masak tebang hanya boleh diambil satu tunas tempel saja.

Hal ini dilakukan masyarakat agar tidak terjadi kerusakan pada pohon belum masak tebang sebab masih dalam proses pertumbuhan. Tinggi bibit yang diambil hanya berukuran antara $\pm 50-60 \mathrm{~cm}$ dengan ukuruan diameter bibit rhizome \pm $13 \mathrm{~cm}$ dan jumlah pelepah sebanyak \pm 4-6 pelepah. Pengambilan bibit sagu dengan ukuran tersebut dimaksudkan oleh masyarakat agar tunas sagu yang demikian telah memiliki cadangan makanan yang cukup baik, dan bila dipindahkan ke tempat lain dapat bertahan dan tumbuh dilingkungan baru.

Bibit pohon sagu yang dikembangkan oleh masyarakat setempat merupakan bibit kedua kultivar yang ada di Kampung Sembaro, yaitu kultivar sagu Akek dan Koror. Menurut masyarakat Kampung Sembaro sagu Akek merupakan sagu bermutu yang harus diwariskan kepada putra pertama. Sagu ini memiliki empulur berwarna merah dan bila dijadikan makanan papeda berwarna putih pekat. Sedangkan sagu Koror yaitu pohon sagu yang lebih mudah dipanen serta dalam penokokan atau penghancuran empulurnya membutuhkan waktu relatif lebih singkat dibandingkan dengan sagu Akek yang ditokok lama (bisa mencapai 1 bulan). Masyarakat sangat menyukai warna empulur sagu Koror yang berwarna kemerahan dan bila dijadikan makanan papeda berwarna putih bening dengan rasa yang lebih enak.

Teknik pengambilan bibit

Proses pengambilan bibit sagu berupa tunas tempel yang sering dilakukan oleh masyarakat Kampung Sembaro yaitu terlebih dahulu masyarakat melakukan pembersihkan pelepah maupun duri-duri pada tunas dan selanjutnya dilakukan pemotongan pangkal bibit yang melekat pada pohon induk secara hati-hati dengan arah tegak lurus ke permukaan tanah ke arah bagian dalam kulit batang pohon induk. Bekas pemotongan diusahakan serata mungkin agar tidak terjadi kerusakan pada bibit. Hal ini sejalan dengan pendapat Haryanto dan Pangloli (1992) yang menyatakan bahwa pemotongan pangkal tunas dilakukan dengan arah tegak lurus kepermukaan tanah dan diusahakan agar bekas potongan serata mungkin. Peralatan yang digunakan dalampembibitan adalah parang.

\section{Penanaman}

\section{Lokasi penanaman}

Di Kampung Sembaro terdapat lima dusun sagu yaitu Sein, Sefru, Sahar, Sembaro dan Atfanges. Areal tersebut merupakan lokasi pengembangan sagu yang telah dilakukan masyarakat Kampung Semabro secara turun temurun. Lokasi penanaman bibit sagu biasanya dipilih daerah yang berdekatan dengan sumber air, serta memiliki tanah berair. Lokasi seperti ini dipilih oleh masyarakat agar tanaman sagu dapat tumbuh dengan baik, mengahasilkan produktifitas yang tinggi serta mudah pada saat pemanenan dan pengolahan. Lokasi penanaman biasanya merupakan tempat kosong atau 
areal bekas kebun yang tidak ditumbuhi pohon besar sehingga bibit yang ditanam dapat tumbuh dengan leluasa serta menerima cahaya matahari secara langsung bagi proses pertumbuhannya.

Tanaman sagu dapat tumbuh dengan baik pada lokasi dengan jumlah curah hujan 2000-4000 mm/tahun yang tersebar merata sepanjang tahun, memiliki kisaran temperatur rata-rata $24-30{ }^{\circ} \mathrm{C}$ dan suhu optimal untuk pertumbuhan berkisar antara 24,50-29 ${ }^{\circ} \mathrm{C}$ dengan kelembaban optimal 60\% (Harsanto 1986).

\section{Cara dan waktu penanaman}

Sebelum melakukan penanaman bibit sagu, biasanya masyarakat melakukan pembersihkan lokasi penanaman dan membuat lubang tanam, kemudian bibit sagu dibenamkan ke dalam lubang tanam dan ditutup dengan tanah. Waktu penanaman bibit bagi masyarakat Kampung Sembaro dapat dilakukan kapan saja, pada pagi, siang atau sore hari sesuai kemauan masyarakat. Berdasarkan pengalaman dalam penanaman bibit, pada saat penanaman tidak boleh duduk membelakangi arah matahari karena akan menghambat pertumbuhan bibit yang ditanam.

Peralatan yang digunakan dalam kegiatan penanaman adalah parang dan kayu, sedangkan linggis dan sekop tidak digunakan karena peralatan ini berat dan tidak dibawa ke dusun sagu. Fungsi dari kedua peralatan tersebut adalah untuk memotong, meruncing dan membuat lubang tanam. Kayu yang digunakan untuk membuat lubang tanam berukuran diameter $\pm 10 \mathrm{~cm}$ dan tinggi $\pm 90 \mathrm{~cm}$.

\section{Jarak tanam}

Ukuran jarak tanam bibit sagu yang digunakan untuk menanam bibit sagu adalah rata-rata $6 \mathrm{~m} \times 6 \mathrm{~m}$ atau berkisar antara 4-8 m. Menurut masyarakat jarak tanam tidak berpengaruh terhadap pertumbuhan tanaman sagu, namun bagi mereka yang harus diperhatikan adalah tempat penanaman karena suatu tanaman dapat tumbuh dengan baik dan menghasilkan produktifitas yang tinggi bergantung pada kondisi tempat tumbuh

\section{Pemeliharaan}

Pemeliharaan tanaman dilakukan pada bibit sagu yang baru ditanam dan tumbuh hingga \pm 2 tahun dengan asumsi telah mengeluarkan tujuh pelepah. Kegiatan ini berupa pembersihan vegetasi dan tanaman pengganggu disekitar areal pertumbuhan, penyulaman bibit sagu yang rusak atau mati serta pemupukan menggunakan bahan kayu lapuk. Peralatan yang digunakan yaitu parang dan kapak.

\section{Pemanenan}

Pertumbuhan sagu di areal dusun sagu pada umumnya berkembang secara alami, demikian juga yang dibudidayakan tidak terlalu mendapat perhatian yang serius karena lebih banyak dibiarkan tumbuh secara alami. Kegiatan penanaman sagu telah dilakukan oleh masyarakat Kampung Sembaro dari generasi kegenerasi secara berkelompok. Sebelum melakukan pemanenan mereka harus mempersiapkan tempat tinggal atau pondok dengan ukuran yang cukup besar. Hal ini karena waktu pemanenan dan penokokan dapat berlangsung lama atau berhari-hari. Dahulu masyarakat tinggal di dusun sagu jika melakukan kegiatan pemanenan sagu. Namun saat ini masyarakat Kampung Sembaro tidak lagi tinggal di lokasi pemanenan sagu, tetapi mereka melakukan aktivitas pulang pergi rumah dari tempat pemanenan di dusun 
sagu setiap hari sampai kegiatan penokokan berakhir. Sampai saat ini masyarakat tetap membangun pondok tetapi hanya sebagai tempat istirahat pada saat makan dan istirahat sebelum pulang dengan ukuran lebar $\pm 200 \mathrm{~cm}$ dan panjang $\pm 300 \mathrm{~cm}$.

Umur panen ideal sagu masak tebang adalah 13-15 tahun, namun bagi masyarakat Kampung Sembaro pemanenan dapat dilakukan pada umur 712 tahun ketika masyarakat kehabisan bahan makanan ataupun terdapat kebutuhan lainnya. Sebelum tanaman sagu dipanen masyarakat Kampung biasanya melakukan pengamatan morfologi pohon ataupun pengetesan empulur dari batang pohon sagu terlebih dahulu. Perlakuan tersebut dilakukan untuk mengetahui tingkat kematangan pohon sagu yang akan diambil empulurnya. Tingkat kematangan ini sangat penting karena berhubungan dengan kandungan aci sagu atau volume aci sagu. Pengamatan terhadap tingkat kematangan pohon sagu masak tebang atau siap panenoleh masyarakat Kampung Sembaro dilakukan dengan dua cara, yaitu berdasarkan pengamatan morfologipohon sagu, dan pengecekan kandungan aci dengan membuat lubang pada batang sagu.

Ciri-ciri morfologi pohon sagu yang digunakan masyarakat setempat untuk mengetahui ada tidaknya pati pada suatu pohon sagu siap panen yaitu ukuran batang pohon sagu telah mencapai diameter 20-60 $\mathrm{cm}$ dengan tinggi pohon $15-27 \mathrm{~cm}$, serta memiliki pelepah daun sagu memendek (manaf), daun menguning (mamium) dan berbunga/berbuah (saker). Ketiga ciri morfologi terakhir merupakan acuan penting bagi masyarakat dalam menentukan pohon sagu siap panen. Hal ini sejalan dengan pendapat (Haryanto dan Pangloli 1992) bahwa masyarakat Papua mengenal ciri-ciri sagu siap panen berdasarkan pelepah daun menjadi pendek, kuncup bunga mulai nampak dan pucuk pohon mendatar. Sedangkan untuk pengetesan empulur, bagian pangkal batang pohon sagu dilubangi untuk mengetahui kandungan aci. Posisi lubang biasanya diperkirakan $\pm 60 \mathrm{~cm}$ dari permukan tanah.

Empulur dari lubang tersebut diambil sebanyak satu genggaman tangan untuk dilakukan pemerasan. Apabila hasil pemerasan diketahui tidak berair maka pohon sagu tersebut memiliki kandungan aci yang cukup tinggi hingga siap dipanen. Ciri morfologi pohon masak tebang dan pembuatan lubang pada batang pohon sagu dan melihat kondisi batang dan kandungan aci.

Cara pemanenan sagu oleh masyarakat Kampung Sembaro tergolong masih semi tradisional yang menggunakan peralatan sederhana. Pada umumnya kegiatan pemanenan terdiri dari beberapa tahapan yaitu:

Pembersihan areal pohon sagu siap panen

Sebelum penebangan dilakukan, areal sekeliling pohon dibersihkan dari vegetasi yang menghalangi ruang gerak dan juga pembersihan lumut pada bagian pangkal batang sagu. Setelah itu pohon sagu siap ditebang. Peralatan yang digunakan dalam kegiatan pembersihan yaitu parang

Pembersihan air untuk pemerasan empulur

Tempat pemerasan biasanya merupakan sungai atau kali kecil yang berada disekitar lokasi penebangan. Sebelum pemerasan empulur terlebih 
dahulu dilakukan pembersihan disekitar areal yang dijadikan lokasi pemerasan termasuk air yang akan digunakan supaya pada waktu ekstraksi air yang digunakan telah menjadi bersih.

\section{Penebangan}

Posisi atau daerah batang sagu yang menjadi area pemotongan biasanya diperkirakan setinggi $\pm 50-70 \mathrm{~cm}$ dari dasar tanah tergantung keadaan topografi. Menurut Haryanto dan Pangloli (1992) pohon sagu siap panen lebih baik ditebang setinggi $\pm 50-100 \mathrm{~cm}$ dari dasar pohon tergantung keadaan topografi. Untuk menentukan arah rebah pohon sagu masyarakat biasanya membuat takik rebah dan takik balas. Teknik tersebut diperoleh secara turun temurun ataupun melalui pengalaman sehari-hari. Setelah pohon sagu ditebang masyarakat memanfaatan pelepah sagu dari pohon tersebut sebagai alat pemerasan dan penampungan aci sagu. Penebagangan pohon sagu dilakukan dengan menggunakan kapak.

Pembuatan tempat pemerasan empulur dan tempat penampung aci sagu

Bahan yang digunakan untuk membuat tempat penampungan aci dan tempat pemerasan terdiri dari pelepah daun sagu. Peralatan yang digunakan dalam kegiatan ini terdiri dari parang serta paku dan palu. Peralatan yang digunakan tersebut cukup modern. Hal ini menunjukkan bahwa masyarakat Kampung Sembaro telah mengalami perubahan sehingga mereka tidak lagi menggunakan peralatan tradisional.

Tempat pemerasan empulur sagu terbuat dari satu buah pelepah yang telah dibersihkan daunnya dan dipotong ujung serta diratakan bagian pangkal hingga berukuran panjang $\pm 150 \mathrm{~cm}$ dan lebar \pm
$50 \mathrm{~cm}$. Kemudian dua batang kayu berdiameter $\pm 7 \mathrm{~cm}$ dan panjang \pm 170 $\mathrm{cm}$ ditancap menyilang sebagai tempat dudukan bagian ujung pelepah yang tingginya $\pm 70 \mathrm{~cm}$ dari permukaan tanah. Lalu bagian kayu yang menyilang diikat menggunakan rotan kecil berukuran diameter $\pm 5 \mathrm{~mm}$. Bagian pangkal pelepah ditutup dengan kain katon tipis yang berukuran panjang $\pm 56 \mathrm{~cm}$ dan lebar $\pm 55 \mathrm{~cm}$ atau menggunakan satu baju kaos katon tipis. Kain tersebut dipaku dibagian pangkal serta bagian ujungnya diikat menggunakan rotan pada sebuah kayu yang telah ditancapkan pada depan bagian pangkal pelepah. Kayu yang di gunakan berukuran diameter $\pm 8 \mathrm{~cm}$ dan panjang $\pm 170 \mathrm{~cm}$.

Tempat penampungan aci sagu terbuat dari dua buah pelepah yang telah dibersihkan daunnya lalu dipotong bagian ujung serta diratakan pangkalnya sehingga berukuran lebar $\pm 50 \mathrm{~cm}$ dan panjang $\pm 200 \mathrm{~cm}$. Kedua pelepah tersebut digabungkan dengan cara memasukan pangkal pelepah yang satu ke pangkal pelepah yang lain sehingga menjadi panjang dengan ukuran \pm 400 $\mathrm{cm}$. Lalu dibuatkan dudukan bagian tengah atau sambungan pelepah tempat penampungan aci. Tempat dudukan penampungan aci sagu terbuat dari enam buah batang kayu berdiameter $\pm 7 \mathrm{~cm}$ dan panjang $100 \mathrm{~cm}$ yang telah disiapkan ditancapkan disisi sebelah kiri tiga dan sisi kanan tiga dengan jarak $\pm 50 \mathrm{~cm}$, dan sama tinggi $\pm 40-50 \mathrm{~cm}$, kemudian tiga buah batang kayu berukuran $\pm 8 \mathrm{~cm}$ dan panjang $\pm 50-60 \mathrm{~cm}$ yang juga telah dipersiapkan untuk menggambungkan antara kayu disisi kiri dan kanan yang telah ditancap menjadi seperti meja sebagai dudukan sambungan tempat 
penampungan. Tempat dudukan yang dibuat diikat menggunakan tali rotan.

Kemudian empat batang kayu dengan ukuran diamteter $\pm 7 \mathrm{~cm}$ dan panjang \pm $170 \mathrm{~cm}$ ditancap menyilang dari masingmasing sisi dan diletakan pada kedua ujung pelepah sebagai tempat dudukan. Masing-masing diikat menggunakan rotan dengan ukuran silangan setinggi \pm $60 \mathrm{~cm}$ dari permukaan tanah.

\section{Pembelahan batang dan pengupasan kulit}

Sebelum kegiatan penokokan dilakukan, bagian batang sagu dibelah menjadi dua bagian. Bagian yang dibelah hanya pada pangkal batang sagu dengan Panjang $\pm 1 \mathrm{~m}$ untuk ditokokan. Hal ini dilakukan karena empulur pada bagian pangkal batang sagu cukup keras dan berdiameter lebih besar dibandingkan dengan bagian batang sagu tengah dan ujung. Proses pembelahan dilakukan dengan cara: batang sagu dipotong/diberi tanda potongan kapak pada sisi kiri dan kanan batang atau pada posisi $\pm^{1 / 2}$ diameter batang, kemudian diambil batang kayu yang telah diruncing untuk dipakai sebagai alat pembelahan batang sagu. Kayu tersebut dimasukkan ke dalam bagian tanda potongan kapak di salah satu sisinnya, lalu kayunya dipukul hingga menembus kesisi sebelah dan kemudian kayunya diangkat hingga kedua bagian batang terpisah atau terbelah menjadi dua bagian dan siap ditokok. Sedangkan bagian batang sagu lainnya hanya dilakukan pengupasan pada bagian kulit batang sagu lalu empulurnya ditokok. Pengupasan dilakukan bertahap sepanjang $\pm 1 \mathrm{~m}$ untuk ditokok.

Alat-alat yang digunakan dalam kegiatan pembersihan, pembelahan dan pengupasan kulit adalah kapak, parang dan kayu. Kayu yang diguankan adalah kayu keras seperti matoa dan merbau yang berukuran panjang $\pm 125 \mathrm{~cm}$ dan diameter $\pm 10 \mathrm{~cm}$.

\section{Penokokan}

Setelah pembelahan dan pengupasan, penokokan dilakukan dengan alat penokok. Proses ekstraksi pati sagu yang dilakukan oleh masyarakat Kampung Sembaro masih bersifat manual atau tradisional. Peralatan penokok terbuat dari bahan kayu berbentuk huruf ' $L$ ' dengan bagian cangkulnya masuk ke dalam, tetapi pada ujung penokok dipasang ring berupa besi putih. Besi tersebut dipasang sebagai alat pemotong atau penghancur empulur ketika diayun atau dipukul ke arah empulur batang. Alat penokok ini hanya terbuat dari kayu matoa (Pometia pinnata) dan merbau (Intsia bijuga), karena kedua kayu tersebut menurut masyarakat sangat kuat.

Cara menokok sagu dilakukan dengan posisi duduk di atas belahan sagu searah belahan batang sagu sambil mengayungkan alat penokok kearah empulur sagu secara berulang kali sehingga empulurnya terpotong atau hancur. Pada saat kegiatan tersebut dilakukan, pada kedua sisi batang harus disediakan karung plastik sebagai tempat menaruh remah empulur sagu hakus dan sisa serat kasar, biasanya dipisahkan remah empulur sagu yang halus ditempatkan pada sisi sebelah dan disisi lainnya sebagai tempat serat yang kasar. Sebelum ada karung plastik dahulu masyarakat menggunakan daun sebagai tempat menaruh remah empulur dan serat kasar.

\section{Pemerasan}

Pemerasan empulur sagu adalah kegiatan atau usaha yang dilakukan dengan mencampurkan rema empulur dengan air lalu diremas-remas serta 
ditapis dengan kain untuk memisahkan atau menghasilkan aci sagu. Kegiatan pemerasan dilakukan dengan mengambil rema empulur sebanyak 4-6 kali gengaman tangan lalu dimasukan ke dalam tempat pemerasan yang telah berisi air. Jumlah air yang dibutuhkan dalam satu kali proses pemerasan yaitu $\pm 2-7$ wadah baskom yang diperkirakan memiliki volume sebanyak 3 liter air. Air yang digunakan berasal dari sungai Aya yang berdekatan dengan areal penebangan sagu.

Hasil ekstraksi sagu pertama berupa larutan aci sagu masih tercampur dengan air sehingga untuk mendapatkan aci sagu larutan tersebut didiamkan selama 30 menit hingga 2 jam agar aci sagu dapat mengendap sesudah itu air dibuang secara perlahan-lahan hingga yang tertinggal hanya aci sagu yang siap di packing. Hasil aci sagu endapan pertama dikhususkan untuk memenuhi kebutuhan sendiri sehingga waktu pengendapan aci sagu cukup singkat. Sementara hasil ekstraksi sagu berikutnya diendapkan selama 4 hari, sehingga hasil endapan maksimal.

\section{Pengemasan (Packing)}

Saat ini proses pengemasan aci sagu oleh masyarakat Kampung Sembaro telah menggunakan karung beras $15 \mathrm{~kg}$. Namun dahulu proses pegemasan dilakukan dengan bambu. Proses perubahan penggunaan bahan pengemasan dari menggunakan wadah bambu menjadi menggunakan wadah karung dipengaruhi oleh perkembangan zaman. Proses pembuatan wadah pengemasan aci sagu dari bambu membutuhkan waktu yang lama, sedangkan wadah karung beras sudah tersedia serta mudah diperoleh dan dibawa kemana saja. Hal ini jugalah yang mempengaruhi penggunaan wadah enampung atau pengemasan aci sagu basah.

\section{Tenaga dan waktu}

Jumlah tenaga kerjadan waktu pengolahan sagu bergantung dari seberapa besar batang sagu yang akan dipanen dan waktu yang diinginkan oleh masyarakat. Jumlah tenaga kerja, waktu dan pembagian pekerjaan dalam pengolahan sagu dapat dilihat pada Tabel 1. Terlihat bahwa jumlah tenaga yang diperlukan dalam proses pemanenan adalah 9-17 orang. Jumlah tenaga yang dibutuhkan pada setiap pekerjaan yaitu 14 orang.

\begin{tabular}{|c|c|c|c|c|c|c|}
\hline \multirow[t]{2}{*}{ No. } & \multirow[t]{2}{*}{ Urutan Pekerjaan } & \multicolumn{3}{|c|}{ Pembagian Kerja } & \multirow{2}{*}{$\begin{array}{l}\text { Jumlah } \\
\text { Tenaga } \\
\text { (orang) }\end{array}$} & \multirow[t]{2}{*}{ Waktu } \\
\hline & & Pria & Wanita & Anak & & \\
\hline 1. & Pembersihan & $\sqrt{ }$ & $\sqrt{ }$ & - & $1-3$ & $15-20$ menit \\
\hline 2. & Penebangan & $\sqrt{ }$ & - & - & 1 & $15-30$ menit \\
\hline 3. & Pembelahan & $\sqrt{ }$ & - & - & $1-2$ & 10-15 menit \\
\hline 4. & Penokokan & $\sqrt{ }$ & - & - & $1-2$ & 300 menit \\
\hline 5. & Pemerasan, & - & $\sqrt{ }$ & - & & $30-60$ menit \\
\hline 6. & Pengemasan & - & $\sqrt{ }$ & - & $1-3$ & $30-1$ jam \\
\hline 7. & Rumah/Pondok & $\sqrt{ }$ & - & - & $\begin{array}{l}1-2 \\
3-4\end{array}$ & 2-3 hari \\
\hline
\end{tabular}




\section{Pemanfaatan}

Tanaman sagu merupakan tumbuhan serbaguna yang dimanfaatkan untuk memenuhi kebutuhan hidup sehari-hari. Bagian-bagian tumbuhan yang dimanfaatkan yaitu pati, daun dan pelepah. Papeda merupakan salah satu makanan pokok bagi masyarakat Papua begitu juga bagi masyarakat Maybrat subetnis Ayamaru di Kampung Sembaro. Proses pembuatannya meliputi: aci sagu disiapkan terlebih dahulu dengan volume sesuai kebutuhan di dalam baskom, sambil air dipanaskan hingga mendidih atau mengeluarkan uap, kemudian air panas dituangkan secara perlahan-lahan dengan gayung ke dalam baskom berisi aci sagu sambil aci sagu diputar-putar perlahan-lahan sampai cepat hingga aci sagu tersebut berubah menjadi berwarna putih bening atau makanan Papeda. Penuangan air harus perlahan-lahan dan tidak boleh terlalu cepat atau berlebihan karena jika demikian maka papedanya tidak jadi. Hal ini juga sebaliknya jika kekurangan air maka papedanya tidak jadi atau masih mentah.

Sagu bakar yang dibuat terdiri dari dua tipe yaitu sagu bakar yang dibungkus dengan daun, dan sagu bakar yang tidak dibungkus dengan daun. Proses pembuatan sagu bakar yang dibungkus menggunakan daun yaitu daun tanaman coklat muda atau daun pisang kering dipersiapkan lalu aci sagu sebanyak dua genggaman tangan diletakan di atas daun kemudian dibungkus dengan cara melipat bagian ujung serta pangkal daun lalu diikat dengan rotan kemudian dimasukan kedalam abu yang telah dipanaskan dan dibiarkan selama setengah jam hingga matang lalu diangkat dan dilepaskan ikatannya dan sagu bakar siap dikonsumsi. Sedangkan untuk sagu bakar yang tidak dibungkus dengan daun cara pembuatannya yaitu diambil segenggaman aci sagu lalu dibulatkan kemudian dikeringkan pada bara api yang telah dipanaskan hingga kering sesudah itu dimasukan kedalam abu yang telah dipanaskan dan dibiarkan selama setengah menit hingga matang kemudian diangkat lalu siap dikonsumsi.

Pembuatan makanan sinoli dimulai dengan menuangkan minyak goreng sebanyak satu sendok makan 1 ke dalam wajan dan dioleskan hingga merata di dalam wajan yang telah diletakan di atas tungku atau kompor dengan api kecil, kemudian aci sagu diambil sebanyak dua genggaman tangan dan dimasukan ke dalam wajan (kuali) sambil diratakan. Selanjunya dituangkan minyak goreng pada seluruh sisi aci sagu sebanyak satu sendok makan lalu dibiarkan hingga matang kemudian diangkat dan sinoli siap dikonsumsi.

\section{Produktifitas Pohon Sagu dan Harga Aci Sagu}

Aci sagu yang dimanfaatkan untuk membuat makanan berasal dari dua kultivar pohon sagu yaitu Akek dan Koror. Produksi aci sagu basah dari satu batang pohon kultivar Akek sebanyak 1012 karung $15 \mathrm{~kg}$. Sedangkan pohon sagu kultivar Koror hanya dapat menghasilkan produksi aci basah sebanyak 5-7 karung $15 \mathrm{~kg}$. Jika dilihat dari hasi produksi tersebut, maka produktifitas sagu Koror lebih rendah dibandingkan Akek. Namun demikian masyarakat lebih menyukai kultivar Koror karena menurut masyarakat Kampung Sembaro waktu penokokannya lebih cepat atau tidak membutuhkan waktu yang cukup lama, serta apabila tepung aci sagunya 

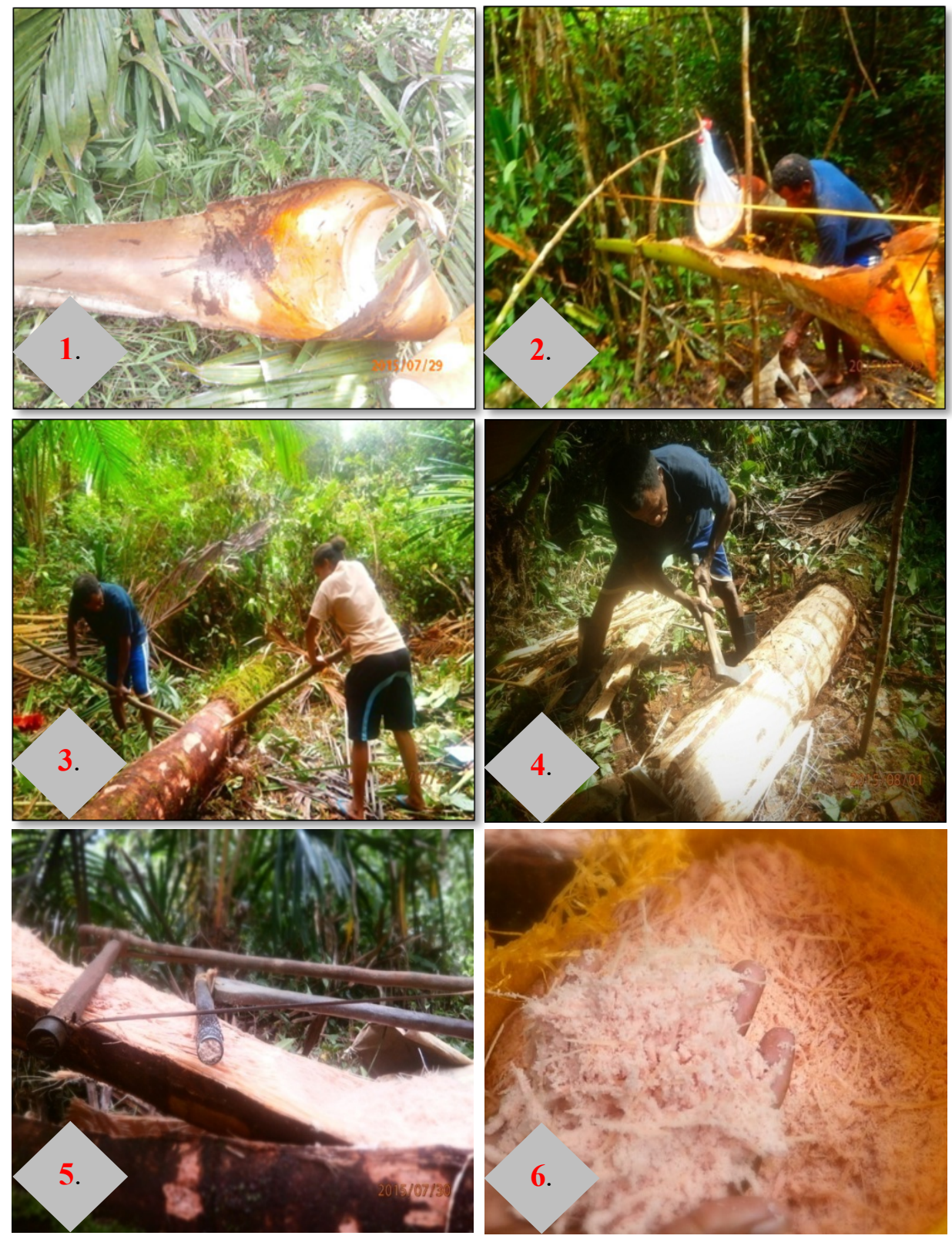

Gambar 1. Alur proses pengolahan sagu berbasis pengetahuan dan budaya masyarakat subetnis Ayamaru. 1). Pelepah sagu dewasa dalam kondisi sehat yang selanjutnya akan digunakan sebagai alur aliran dalam proses remas; 2). Proses ekstraksi tepung aci sagu dengan menggunakan air; 3). Pembersihan batang sagu dewasa sebelum dibelah; 4). Proses pembelahan batang sagu guna memudahkan pengambilan tepung aci; 5). Tahapan tokok/penghancuran batang guna mengambil tepung aci dengan menggunakan peralatan penokok (ramo); 6). Hasil tokok yang masih bercampur antara serat dan tepung aci. 
dibuatkan makanan papeda warnanya putih bening dengan cita rasa yang lebih enak dibandingkan dengan kultivar koror.

Produksi aci basah dari pohon sagu di setiap daerah berbeda-beda, begitupula tiap varietas di dalam satu daerah maupun berbeda daerah, seperti hasil penelitian
Kadiwaru (2004) di Kampung Mariadei Distrik Yapen Selatan. Aci sagu basah yang dapat dihasilkan dari satu pohon sagu masak tebang yaitu sebanyak 6-15 tumang. Data produksi pati/tepung aci sagu basah per pohon sagu di beberapa lokasi dapat dlihat pada Tabel 2.

Tabel 2. Produksi tepung/pati (aci) sagu basah per pohon pada beberapa lokasi.

\begin{tabular}{ccll}
\hline No. & $\begin{array}{c}\text { Produksi Aci Sagu Basah } \\
\text { Per Pohon }\end{array}$ & \multicolumn{1}{c}{ Lokasi } & \multicolumn{1}{c}{ Sumber } \\
\hline 1. & 250 & Jayapura & Flach 1983 \\
2. & 226 & Maluku & Unpati 1992 \\
3. & 237 & Maluku & DPTB 1979 \\
4. & $300-700$ & Papua & Uncn 1979 \\
5. & $623,29-874,9$ & Yapen Waropen & Makabori 1991 \\
6. & $90-325$ & Salawati & Vetger dkk (1983) \\
\hline
\end{tabular}

Sumber: Kambuaya (2001)

Harga sagu yang dipasarkan oleh masyarakat Kampung Sembaro yaitu sebesar Rp. 350.000/karung 15 kg. Harga tersebut merupakan harga jual disekitar kampung, namun kalau dijual diluar kampung harganya lebih tinggi dari harga tersebut.

\section{DAFTAR PUSTAKA}

Alhamid HYO, Lekitoo dan Sumitro. 1996. Aspek sosial ekonomi dan sosial budaya masyarakat peramu sagu disekitar Teluk Bintuni. Jurnal Penelitian Kehutanan, Vol 3(1). Departemen Kehutanan. Manokwari.

Assem K, Peday MH dan Rumatora A. 2018. Pemanfaatan dan bentuk pengolahan kulit kayu berbasis pengetahuan lokal dan identitas budaya masyarakat Maybrat. Jurnal Kehutanan Papuasia, Vol 4 (1): 34-44.

Fakultas Kehutanan Universitas Papua. 2014. Tim peneliti sago (Biomass Resource Assessment) di Kampung Poom I Kabupaten Kepulauan Yapen.
Flach M. 1983. The sago palm demostication exploitation and product. FAO Plant Production and Protection Paper. Roma.

Harsanto PB. 1986. Budidaya dan pengelolaan sagu. Penerbit Kanisius. Yogyakarta.

Haryanto B dan P Pangloli. 1992. Potensi dan pemanfaatan sagu. Penerbit Kanisius. Yogyakarta.

Kadiwaru I. 2004. Teknik pembibitan dan penanaman sagu (Metroxylon sago Rottb.) oleh penduduk Poom I Distrik Poom Kabupaten Yapen. Skripsi Sarjana Kehutanan Universitas Negeri Papua Manokwari. (Tidak diterbitkan).

Kambuaya VT. 2001. Produksi aci sagu (Metroxylon Sagu Rottb.) oleh petani peramu di Kecamatan Inanwatan Kabupaten Sorong. Skripsi Sarjana Kehutanan Universitas Negeri Papua Manokwari. (Tidak diterbitkan).

Lekitoo K, Peday HFZ, Panambe N and Cabuy RL. 2017. Ecological and ethnobotanical facet of 'Kelapa Hutan' 
(Pandanus spp.) and perspectives towards its existence and benefit. International Journal of Botany, 13: 103-114.

Marwa J, Cabuy RL dan Tawer AY. 2013. Potential and pattern of utilization of renewable energy sources from vegetation based on local knowledge of Ireres tribe in Tambrauw, West Papua, Indonesia. Indian Journal of Traditional Knowledge, 12 (3): 411-417.

Payai A. 2008. Proses pengolahan pati sagu (Metroxylon spp.) secara tradisional oleh masyarakat Kampung Mariadei Distrik Yapen Selatan Kabupaten Yapen Waropen. Skripsi
Sarjana Kehutanan Universitas Negeri Papua Manokwari. (Tidak Diterbitkan).

Salosa YPS. 1997. Teknik pembibitan dan penanaman sagu (Metroxylon Spp.) masyarakat Inanwatan Kabupaten Sorong. Skripsi Sarjana Kehutanan Fakultas Pertanian Universitas Cendrawasih Manokwari. (Tidak diterbitkan).

Suebu AS. 2005. Teknik pembibitan dan penanaman sagu (Metroxylon Sagu Rottb.) di Kampung Nendali Distrik Sentani Kabupaten Jayapura. Skripsi Sarjana Kehutanan Universitas Negeri Papua Manokwari. (Tidak diterbitkan). 